\title{
Letter to the Editors: \\ Relations between subjective well-being and Alzheimer's disease: a systematic review
}

\author{
Vitor Maia Arca', Laiza de Oliveira Lucena', Breno José Alencar Pires Barbosa',2
}

Dear Editor,

W e read with great interest the article by Moura et al. entitled "Relations between subjective well-being and Alzheimer's disease: a systematic review". ${ }^{1}$ In the study, the authors performed a comprehensive systematic review of the literature to evaluate the methodological quality of studies addressing Subjective Well-Being (SWD) in Alzheimer disease (AD). Given the importance of this discussion and the fact that most neurologists may not be familiar with SWB measures (ourselves included), we missed a more detailed description of the instruments used in the articles, as well as their potential strengths and limitations. We observed that 11 different SWB measurement tools were used in the 13 articles reported. The quality of life in
AD (QoL-AD) scale by Longsdon et al. ${ }^{2}$ was the most used tool, being reported in 5 of the 13 studies. The instrument has been translated into Portuguese and consists of 13 items related to physical health, humor, memory, task performance, interpersonal relations, and leisure activities. ${ }^{3} \mathrm{~A}$ review pointed out that QoL-AD was the best-researched measure, since it is available both in the self-rating and proxy-rating versions. ${ }^{4}$ Another point to be considered in the review by Moura et al. was the low number of results found on the PubMed platform as compared to the other searched databases. We tried to conduct the same inquiry and found a significantly higher number of studies, which led us to wonder whether other filters could have been used. We believe further studies in the field to be extremely welcome.

\section{REFERENCES}

1. Moura FP, Hamdan AC. Relations between subjective well-being and Alzheimer's disease: a systematic review. Dement Neuropsychol. 2020;1(2):153-8. https://doi. org/10.1590/1980-57642020dn14-020008

2. Logsdon RG, Gibbons LE, McCurry SM, Teri L. Quality of life in Alzheimer's disease: patient and caregiver reports. J Mental Health Aging [Internet]. 1999;5(1):21-32 [accessed on Aug. 10, 2020]. Available at: https://www.researchgate.net/profile/ Susan_Mccurry/publication/232417911_Quality_ of_Life_in_Alzheimer's_disease_Patient_and_Care-
giver_Reports/links/00b7d536bb4ef116f2000000/ Quality-of-Life-in-Alzheimers-disease-Patient-and-Caregiver-Reports.pdf

3. Pinheiro AP. Instrumentos de avaliação da qualidade de vida na demência. RPMGF. 2019;35(6):481-8. http:// dx.doi.org/10.32385/rpmgf.v35i6.12391

4. Bowling A, Rowe G, Adams S, Sands P, Samsi K, Crane M, et al. Quality of life in dementia: a systematically conducted narrative review of dementia-specific measurement scales. Aging Ment Health. 2015;19(1):13-31. https://doi.org/10. 1080/13607863.2014.915923 


\title{
Authors' response: \\ Relations between subjective well-being and Alzheimer's disease: a systematic review
}

\author{
Fernanda Panage Mouraª, Amer Cavalheiro Hamdan
}

To the Editor,

F rst, we would like to thank the reader for the letter commenting on our paper. ${ }^{1}$ Some points can be clarified in response to the questions. The smaller number of articles found in PubMed, in relation to other platforms, is probably explained by the fact that it is aimed especially at medical studies. The term "Well-Being", when used as a search keyword, was more frequent on platforms that cover research in other areas, such as psychology.

The search for articles was established according to previously defined inclusion and exclusion criteria, explained in the paper. On the PubMed platform, these criteria were included according to the filters shown in Table 1.

Regarding criterion A, "Aged 65+ years" was selected. It should be noted that, on this platform, there were no other age options related to the aged population. Regarding criterion C, the search covered the last five years and was carried out in June 2019. Therefore, the filter to be used must be specified between June 2014 and June 2019.

Regarding the use of search terms, some relevant aspects need to be highlighted. The terms "Well-Being"
AND "Alzheimer" were used in the title and summary of the studies. The search result was recently reproduced and can be found at https://drive.google.com/file/d/1DYxw6B6qZp6ZWrM1Iegnf5dMviUT64mV/view?usp=sharing

Finally, we share the same opinion regarding the concept of "Well-Being." The same should be investigated more deeply in the different health areas. We appreciate your comments and questions regarding the article. In this way, we can improve future research and disseminate knowledge on this very current and relevant topic.

Table 1. Inclusion criteria and filters for the selection of articles.

\begin{tabular}{lcc}
\hline Inclusion criteria & Filter & Criteria selected \\
\hline $\begin{array}{l}\text { Criteria A } \\
\text { Articles with a sample of } \\
\text { the elderly population }\end{array}$ & Age & Aged: $65+$ years. \\
\hline $\begin{array}{l}\text { Criteria B } \\
\text { Empirical articles }\end{array}$ & Article type & $\begin{array}{c}\text { Clinical trial; controlled } \\
\text { clinical trial; and } \\
\text { randomized trial }\end{array}$ \\
\hline $\begin{array}{l}\text { Criteria C } \\
\text { Articles published } \\
\text { from 2014 to 2019 }\end{array}$ & $\begin{array}{l}\text { Results } \\
\text { by year }\end{array}$ & $\begin{array}{c}\text { 01 June 01, 2014 to } \\
\text { 01 June 01, 2019 }\end{array}$ \\
\hline
\end{tabular}

\section{REFERENCE}

1. Moura FP, Hamdan AC. Relations between subjective well-being and Alzheimer's disease: A systematic review. Dement Neuropsychol. 2020;14(2):153-8. https://doi.org/10.1590/1980-57642020dn14-020008 